Article

\title{
The Syntheses, Crystal Structure and Luminescence Properties of Cone-Like Octadentate Europium (III) Complexes with Four Short Alkoxy Substituents
}

\author{
Tetsuji Moriguchi ${ }^{1, *}$, Satoshi Hirosaki ${ }^{1}$, Venkataprasad Jalli ${ }^{1}$, Akihiko Tsuge ${ }^{1}$ and Kenji Yoza ${ }^{2}$ \\ 1 Department of Applied Chemistry, Faculty of Engineering, Kyushu Institute of Technology, 1-1 Sensui-cho, \\ Tobata-ku, Kitakyushu 804-8550, Japan; e.a.3104@gmail.com (S.H.); jvprasad.008@gmail.com (V.J.); \\ tsuge@che.kyutech.ac.jp (A.T.) \\ 2 Japan Bruker AXS K.K, 3-9, Moriya-cho Kanagawaku, Yokohama 221-0022, Japan; Kenji.Yoza@bruker.com \\ * Correspondence: moriguch@che.kyutech.ac.jp; Tel.: +81-93-884-3330
}

Academic Editor: Ingo Hartenbach

Received: 27 February 2017; Accepted: 8 March 2017; Published: 13 March 2017

\begin{abstract}
Treatment of 1-(4'-methoxy or ethoxy phenyl)-4,4,4-trifluoro-1,3-butanedione with europium (III) chloride in the presence of piperidine resulted in the halide ligands exchange yielded new piperidinium tetrakis\{1-(4'-methoxy or ethoxy phenyl)-4,4,4-trifluoro-1,3-butanedionato $\}$ europate (III) complexes $\mathbf{2} \mathbf{a}$ and $\mathbf{2} \mathbf{b}$. Complexes $\mathbf{2} \mathbf{a}$ and $\mathbf{2} \mathbf{b}$ have been characterized by elemental analysis, ${ }^{1} \mathrm{H}$ NMR spectroscopy, and FAB-MS, and their absolute structures were determined by single crystal $\mathbf{X}$-ray diffraction analysis. The complexes $\mathbf{2 a}$ and $\mathbf{2 b}$ have the monoclinic space groups $\mathrm{C} 2 / \mathrm{c}\left(\mathrm{No} .15,4^{\prime}\right.$-substituent $\left.=\mathrm{OCH}_{3}\right)$ and with $P-1\left(\mathrm{No} .2,4^{\prime}\right.$-substituent $\left.=\mathrm{OC}_{2} \mathrm{H}_{5}\right)$, respectively. $\mathrm{X}$-ray analysis results showed that eight coordinate structures of the complexes $\mathbf{2 a}$ and $\mathbf{2} \mathbf{b}$ have cone-like structures, like calix[4]arenes, but their structures were slightly different due to the crystal packing and the existence of the solvent molecule. The complexes $\mathbf{2 a}$ and $\mathbf{2} \mathbf{b}$ exhibited identical, strong photoluminescence emissions in the solution phase.
\end{abstract}

Keywords: europium complex; fluorescence; X-ray analyses; crystallization solvent

\section{Introduction}

The luminescent properties of Lanthanide complexes with various organic ligands have been investigated for decades [1], and the search for novel Lanthanide complexes continues to attract many researchers due to their important applications as optical fiber lasers, electroluminescent displays, and organic light emitting diodes [2-4]. Among these, europium (III) complexes with $\beta$-diketones possessing aromatics and fluorine substituents displayed very good to excellent photo luminescent properties. Thus, various europium (III) complexes with $\beta$-diketones were synthesized and evaluated for their photo luminescent properties [4-9].

In this context, we report the synthesis, structural, and spectral properties of the octa-coordinate europium (III) complexes carrying four bidentate $\beta$-diketonato ligands having four alkoxy substituted aromatic moieties, fluorine substituents, and one piperidinium as a counter cation. Further, we have investigated the structural properties using $\mathrm{X}$-ray analyses.

The luminescent intensity of the complexes $\mathbf{2 a}$ and $\mathbf{2 b}$ was quite strong because the complex has no water ligand in solid and in solution. This is due to the vibration relaxation of water molecule; that is to say, the excited energy on the forbital ( $\left({ }^{5} \mathrm{D}\right.$ levels) of the centered europium ion is effectively relaxed to ${ }^{7} \mathrm{~F}$ levels. 


\section{Results and Discussion}

\section{Synthesis and Spectra Analysis}

The two complexes $\mathbf{2 a}$ and $\mathbf{2} \mathbf{b}$ were synthesized in two steps. In the first step, $\beta$-diketone ligands were prepared by Claisen condensation of $4^{\prime}$-methoxy and ethoxy acetophenone with ethyl trifluoroacetate using sodium hydride as a base in THF. Secondly, 1-(4'-methoxy or ethoxy phenyl)-4,4,4-trifluoro-1,3-butanedione $\mathbf{1 a}$ and $\mathbf{1} \mathbf{b}$ reacted with europium (III) chloride in the presence of piperidine as a base reagent in ethanol solvent according to the method reported in the literature, yielding the corresponding complexes $\mathbf{2} \mathbf{a}$ and $\mathbf{2} \mathbf{b}$ in very good yields [10]. Complexes $\mathbf{2} \mathbf{a}$ and $\mathbf{2} \mathbf{b}$ are stable under air and moisture conditions. Structural properties in solution are in line with expectations, as shown by ${ }^{1} \mathrm{H}$ NMR spectroscopy. Although the peaks of the complexes are quite shifted from normal regions due to paramagnetic effect of the europium (III) ion, it can be easily assigned.

In the mass spectrum of $\mathbf{2 a}$, the fragment peak is $m / z 888\left([\mathrm{M}+\mathrm{H}]^{+}-1\right.$ ligand - piperidinium cation) mainly appears. However, the peak $m / z 1133\left([\mathrm{M}+\mathrm{H}]^{+}-\right.$piperidinium cation $)$is quite small. In addition, in the mass spectrum of $\mathbf{2 b}$, the main fragment peak is $m / z 930\left([\mathrm{M}+\mathrm{H}]^{+}-1\right.$ ligand piperidinium cation) with the small peak $m / z 1189\left([\mathrm{M}+\mathrm{H}]^{+}-\right.$piperidinium cation). This is well explained by the fact that the neutral fragment is more stable than that of the anionic fragment ion.

The UV-vis absorptions for the ligands $(\mathbf{1 a}, \mathbf{1 b})$ and their corresponding europium complexes $(\mathbf{2 a}, \mathbf{2 b})$ were measured in dichloromethane solution $\left(1 \times 10^{-3} \mathrm{~mol} / \mathrm{L}\right)$, and their corresponding spectra is shown in Figures 1 and 2. The ligands showed strong absorption bands at $352 \mathrm{~nm}$ and $351 \mathrm{~nm}$, respectively. These strong absorption bands were assigned to the $\pi-\pi^{*}$ enol absorptions of the $\beta$-diketone ligands. Relatively low intensity absorption bands at $246 \mathrm{~nm}$ and $244 \mathrm{~nm}$ were assigned to the $\mathrm{n}-\pi^{*}$ enol absorptions of the $\beta$-diketone ligands. Complexes $\mathbf{2} \mathbf{a}$ and $\mathbf{2} \mathbf{b}$ exhibited broad high intensity absorption bands from 342nm to $356 \mathrm{~nm}$, respectively. The absorption coefficients (log $\varepsilon$ ) of the complexes $\mathbf{2 a}$ and $\mathbf{2 b}$ were 3.10 and 3.15, respectively. This was attributed to the chelating of four $\beta$-diketone ligands with the europium (III) ion.

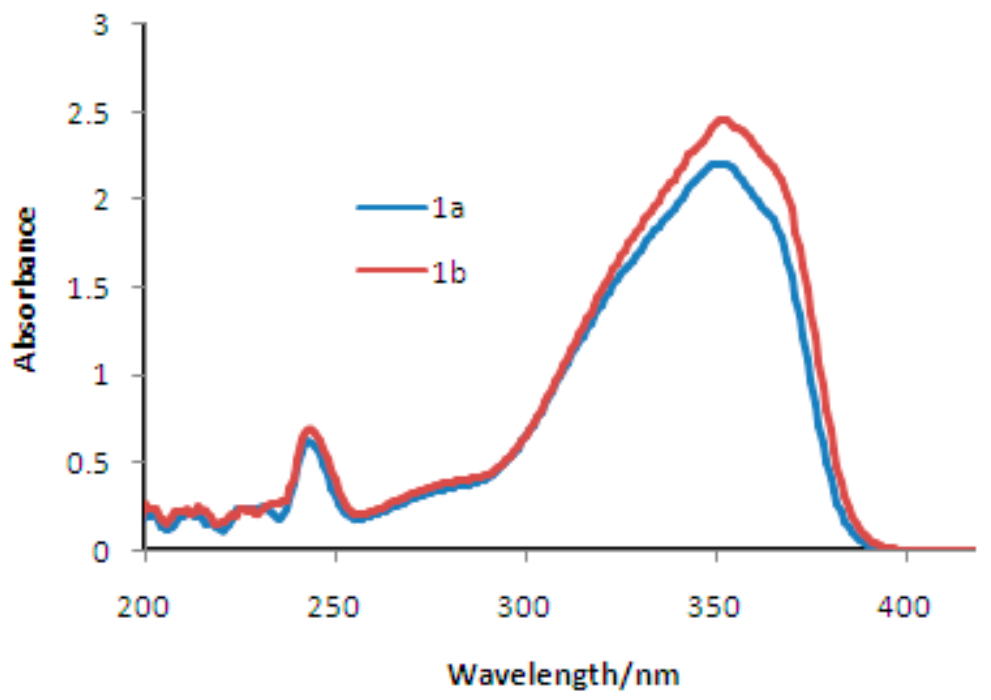

Figure 1. UV-Visible spectra of the ligands $\mathbf{1 a}$ and $\mathbf{1 b}$.

The emission spectra of the complexes $\mathbf{2 a}$ and $\mathbf{2} \mathbf{b}$ was recorded in dichloromethane solution $\left(1 \times 10^{-3} \mathrm{~mol} / \mathrm{L}\right)$, and their emission spectra is shown in Figure 3. Emission spectra of the complexes were measured by exciting the complexes at their absorption maximum wavelengths $352 \mathrm{~nm}$ and $351 \mathrm{~nm}$, respectively. The emission spectra of the complexes $\mathbf{2} \mathbf{a}$ and $\mathbf{2} \mathbf{b}$ showed sharp peaks in the region 590-720 nm associated with ${ }^{5} \mathrm{D}_{0} \rightarrow{ }^{7} \mathrm{~F}_{J}(J=0-4)$ transitions of the europium (III) ion. The very high intensity peak was observed at $613 \mathrm{~nm}$ due to the ${ }^{5} \mathrm{D}_{0} \rightarrow{ }^{7} \mathrm{~F}_{2}$ transition, suggesting 
a highly polarizable chemical environment around the europium (III) ion [11]. This transition was responsible for the red emission of the complexes $\mathbf{2} \mathbf{a}$ and $\mathbf{2} \mathbf{b}$. The emission and absorption spectra of complexes $\mathbf{2 a}$ and $\mathbf{2} \mathbf{b}$ are almost identical, suggesting that the changing substitution on $\beta$-diketone ligands from methoxy to ethoxy did not affect the luminescent properties of the complexes $\mathbf{2 a}$ and $\mathbf{2} \mathbf{b}$.

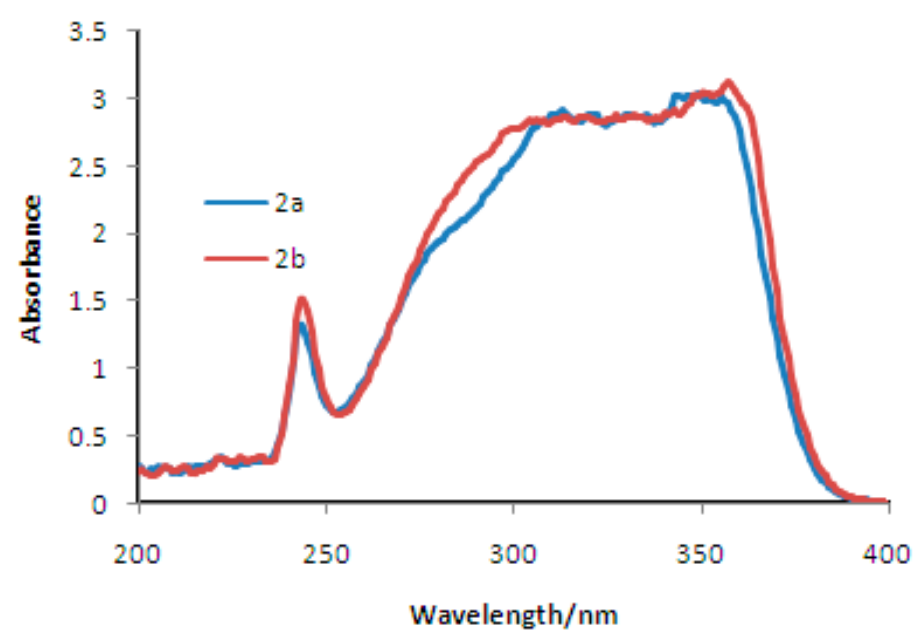

Figure 2. UV-Visible spectra of the complexes $\mathbf{2 a}$ and $\mathbf{2 b}$.

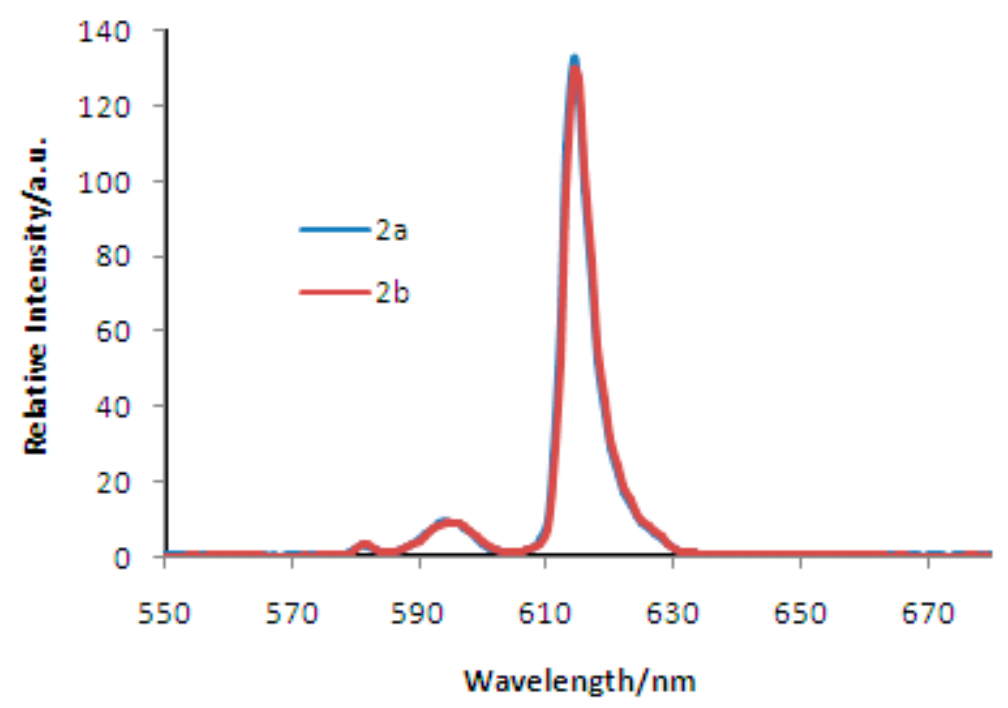

Figure 3. Emission spectra of the complexes $2 \mathbf{a}$ and $\mathbf{2 b}$.

To further confirm the absolute structures of complexes $\mathbf{2 a}$ and $\mathbf{2} \mathbf{b}$, suitable single crystals for $X$-ray structure analysis were easily obtained in ethanol solvent using a slow evaporation method. The complex 2a crystallizes in the monoclinic space group C2/c (centrosymmetric, No. 15), the cell unit includes four molecules with four piperidinium ions and with no solvate molecule (Figure 4).

The complex $\mathbf{2} \mathbf{b}$ crystallizes in the monoclinic space group $P-1$ (non-centrosymmetric, No. 2), the cell unit includes two molecules with two piperidinium ions and with two chloroform molecules (Figure 4). 

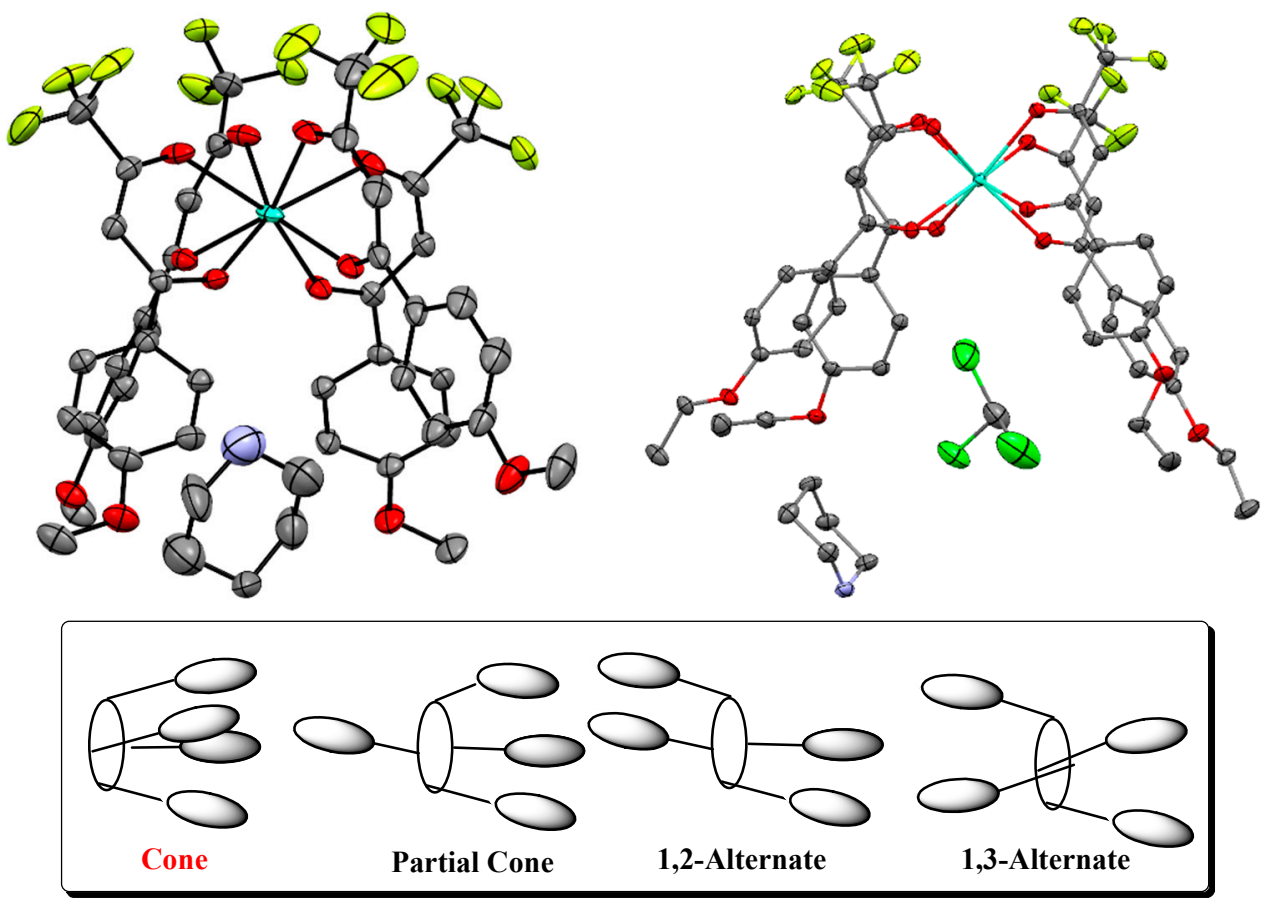

Figure 4. ORTEP view of the complexes $2 \mathbf{a}$ (left) and $\mathbf{2 b}$ (right). Ellipsoids are drawn at $50 \%$ probability level. Aqua blue, palegreen, blue, red and green ellipsoids show Eu, F, N, O, and $\mathrm{Cl}$ atom(s), respectively.

The europium (III) ions of $\mathbf{2} \mathbf{a}$ and $\mathbf{2} \mathbf{b}$ are coordinated by a distorted octahedral arrangement of eight oxygen atoms from four chelating $\beta$-diketonato ligands (Figure 5). The average Eu1-O (1-8) bond lengths are moderately normal, and these values are ca. $2.357 \AA$ for $\mathbf{2 a}$ and $2.392 \AA$ for $\mathbf{2} \mathbf{b}$, respectively. The bond angles in the five membered rings consisting of $\mathrm{Eu}$ and 1,3-butanedionato ligands (O-Eu-O) vary from $71.83(15)^{\circ}$ to $73.60(16)^{\circ}$ for $\mathbf{2 a}, 70.41(8)^{\circ}$ to $71.81(8)^{\circ}$ for $\mathbf{2} \mathbf{b}$, respectively (Tables 1 and 2 ). These values of bond distances and bond angles are in good agreement with those reported for other analogous europium $\beta$-diketonato complexes [12]. The piperidinium cation involving the $\mathrm{N} 1$ atom is the most stable chair form in the crystal, and located near the crystallized benzene molecules (Figure 4).
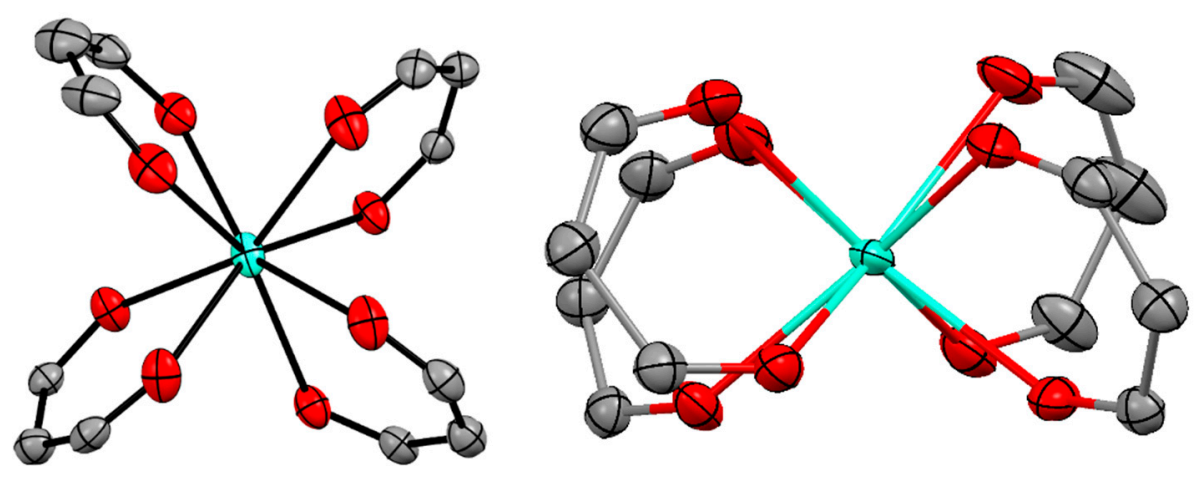

Figure 5. Top views of eight coordinate structures of europium (III) ion for $\mathbf{2 a}$ (left) and $\mathbf{2 b}$ (right). Aqua blue and red ellipsoids show Eu and $\mathrm{O}$ atoms, respectively. 
Table 1. Selected bond lengths $(\AA)$ and angles $\left(^{\circ}\right)$ for the complex $2 \mathbf{a}$.

\begin{tabular}{cccc}
\hline Eu1-O1 & $2.383(5)$ & Eu1-O2 & $2.351(5)$ \\
\hline Eu1-O4 & $2.373(4)$ & Eu1-O5 & $2.331(4)$ \\
Eu1-O7 & $2.381(5)$ & Eu1-O8 & $2.373(5)$ \\
Eu1-O10 & $2.350(6)$ & Eu1-O11 & $2.316(4)$ \\
O1-Eu1-O2 & $73.60(16)$ & O4-Eu1-O5 & $72.67(14)$ \\
O7-Eu1-O8 & $71.83(15)$ & O10-Eu1-O11 & $72.26(14)$ \\
\hline
\end{tabular}

Table 2. Selected bond lengths $(\AA)$ and angles $\left(^{\circ}\right)$ for the complex $\mathbf{2 b}$.

\begin{tabular}{cccc}
\hline Eu1-O1 & $2.404(3)$ & Eu1-O2 & $2.371(3)$ \\
\hline Eu1-O4 & $2.439(2)$ & Eu1-O5 & $2.339(3)$ \\
Eu1-O7 & $2.411(2)$ & Eu1-O8 & $2.424(3)$ \\
Eu1-O10 & $2.420(2)$ & Eu1-O11 & $2.331(2)$ \\
O1-Eu1-O2 & $70.41(8)$ & O4-Eu1-O5 & $70.63(8)$ \\
O7-Eu1-O8 & $71.19(8)$ & O10-Eu1-O11 & $71.81(8)$ \\
\hline
\end{tabular}

Molecular shapes of these complexes are cone-like structures and the complex molecules have cavities (Figure 4). The difference between $\mathbf{2} \mathbf{a}$ and $\mathbf{2} \mathbf{b}$ about the inclusion of solvate molecule is well explained by the difference of the largeness of the cavity consisting of the four ligands. The cavity size of the $\mathbf{2 b}$ complexes seems to be larger than those of $\mathbf{2 a}$. Differences between these complexes and calix[4]arene are the environment's internal cavity spaces; in another words, aromatic parts on the calixarenes are oriented-electron surfaces to the cavity center. On the contrary, the aromatic parts on the complexes are aromatic $\mathrm{C}-\mathrm{H}$ protons oriented to the cavity center (Figure 6). Therefore, the complexes are expected as new compounds for undeveloped fields of host-guest chemistry.

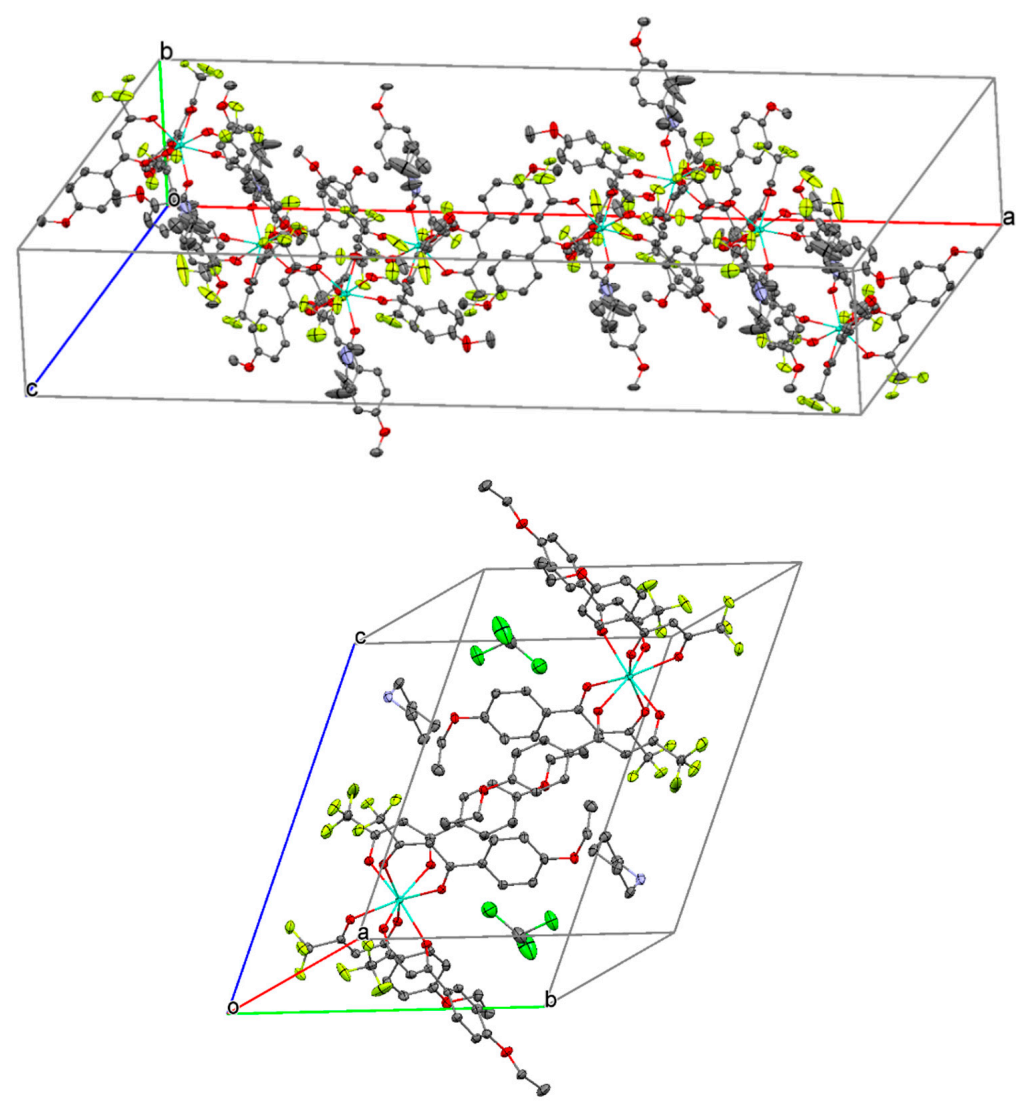

Figure 6. Crystal packing diagram of the complexes $\mathbf{2 a}$ (above) and $\mathbf{2 b}$ (below). Aqua blue, pale green, darkblue, red, and green ellipsoids show $\mathrm{Eu}, \mathrm{F}, \mathrm{N}, \mathrm{O}$, and $\mathrm{Cl}$ atoms, respectively. 


\section{Experiments}

\subsection{Materials and Instrumentation}

All reagents and solvents were obtained from commercial sources and are used without further purification. The ${ }^{1} \mathrm{H}-\mathrm{NMR}$ spectra were recorded on a Bruker AVANCE400S spectrometer (Bruker, Yokohama, Japan) in $\mathrm{CDCl}_{3}$ with tetramethylsilane $\left(\mathrm{Me}_{4} \mathrm{Si}\right)$ as an internal reference. The positive fast atom bombardment (FAB) mass spectrum (MS) of the complex were obtained on a Nippon Densi JEOL JMS-SX102A spectrometer (JEOL, Tokyo, Japan) using NBA (nitrobenzylalcohol) as the matrix and DCM (dichloromethane) as the solvent. The instrument was operated in positive ion mode over an $m / z$ range of 100-2000. Elemental analysis data were recorded on a Yanako MT-4 analyzer (Yanako Group, Kyoto, Japan). A JASCO V-550 spectrophotometer (JASCO Corporation, Tokyo, Japan) was used for obtaining UV-Vis spectra in dichloromethane with 250-900 nm range. HITACHI F-2500 spectrophotometer (Hitachi High-Technologies Corporation, Tokyo, Japan) was used for fluorescence spectra measurements in dichloromethane with 250-900 nm range. CCDC No. 1529390 and 1529592 contain the supplementary crystallographic data for the complexes $\mathbf{2} \mathbf{a}$ and $\mathbf{2} \mathbf{b}$, respectively.

\subsection{Synthesis}

3.2.1. Preparation of Piperidinium Tetrakis $\left\{1-\left(4^{\prime}\right.\right.$-substituted phenyl)-4,4,4-trifluoro-1,3butanedionato\}europate (III) Complexes $\mathbf{2 a}$ and $\mathbf{2 b}()$

Typical Procedure

In a first Schlenk vessel, a solution of europium (III) chloride $(0.650 \mathrm{~g}, 0.41 \mathrm{mmol})$ and 1-(4'-methoxy or ethoxy phenyl)-4,4,4-trifluoro-1,3-butanedione $\mathbf{1}(1.65 \mathrm{mmol})$ in absolute ethanol $(30 \mathrm{~mL})$ was prepared at room temperature. Under protection from air, a slight excess of piperidine $(0.30 \mathrm{~mL}, 3.0 \mathrm{mmol})$ was added to the solution, and the two solutions were then combined and stirred at room temperature for $12 \mathrm{~h}$. After filtration, piperidine and most volatile materials were removed from the filtrate on a vacuum line. Under protection from air, the residue was repeatedly washed with small portions $(5 \mathrm{~mL})$ of warm, dry ethanol. The residual powders were dissolved with ethanol for crystallization. Without protection from air, the crystallized product was filtered off, washed with two portions of cold ethanol, and dried under reduced pressure, affording $0.371 \mathrm{~g}$ of pale-yellow piperidinium tetrakis(1-(4'-methoxy or ethoxy phenyl)-4,4,4-trifluoro-1,3-butanedionato)europate (III) as a powder in $80 \%$ yield.

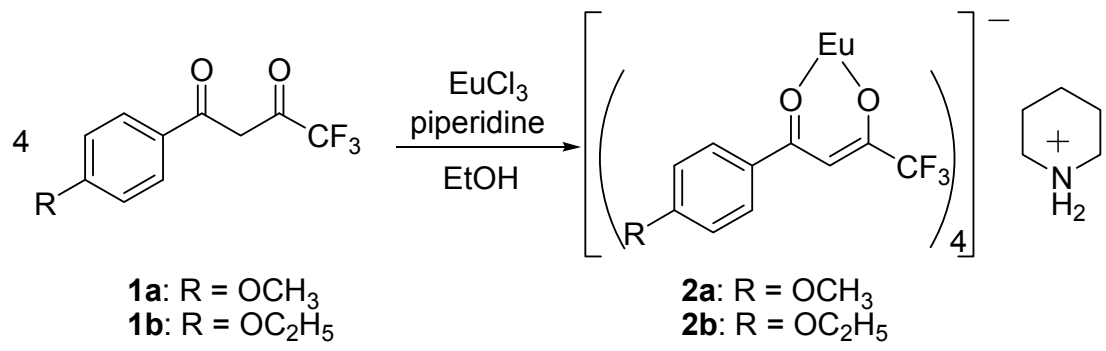

Scheme 1. Synthesis of the complexes $\mathbf{2 a}$ and $\mathbf{2 b}$.

3.2.2. Piperidinium Tetrakis $\{1$-(4'-methoxy phenyl)-4,4,4-trifluoro-1,3-butanedionato\}europate (III) $2 \mathbf{a}$

M.p: $186-189{ }^{\circ} \mathrm{C} .{ }^{1} \mathrm{H}$ NMR $\left(400 \mathrm{MHz}, \mathrm{CDCl}_{3}\right) \delta_{\mathrm{H}} 1.78$ (br s, $2 \mathrm{H}$, piperidinium), 2.05 (br s, $4 \mathrm{H}$, piperidinium), 3.47 (br s, $4 \mathrm{H}$, piperidinium), 3.95 (s, $12 \mathrm{H}, \mathrm{OCH}$ ), 5.04 (s, $4 \mathrm{H}, \beta$-diketonato), 6.95 (br s, $8 \mathrm{H}$, phenyl), 7.99 (br s, $8 \mathrm{H}$, phenyl). Pos. FAB-MS: $m / z 888\left([\mathrm{M}+\mathrm{H}]^{+}-1\right.$ ligand - piperidinium cation), $1133\left([\mathrm{M}+\mathrm{H}]^{+}\right.$- piperidinium cation). Elemental analysis calcd. For $\mathrm{C}_{49} \mathrm{H}_{44} \mathrm{EuF}_{12} \mathrm{NO}_{12}$ : $\mathrm{Eu}, 12.47 \%$; C, $48.29 \%$; H, 3.64\%; N, $1.15 \%$. Found: Eu, $12.40 \%$; C, $48.03 \%$; H, 3.87\%; N, $1.29 \%$. 
3.2.3. Piperidinium Tetrakis $\left\{1-\left(4^{\prime}\right.\right.$-ethoxy phenyl)-4,4,4-trifluoro-1,3-butanedionato\}europate (III) $2 \mathbf{b}$

M.p: $148-150{ }^{\circ} \mathrm{C} .{ }^{1} \mathrm{H}$ NMR $\left(400 \mathrm{MHz}, \mathrm{CDCl}_{3}\right) \delta_{\mathrm{H}} 1.49\left(\mathrm{~d}, 12 \mathrm{H}, \mathrm{OC}_{2} \mathrm{H}_{5}, J=6 \mathrm{~Hz}\right), 1.78$ (br s, $2 \mathrm{H}$, piperidinium), 2.05 (br s, $4 \mathrm{H}$, piperidinium), 3.47 (br s, $4 \mathrm{H}$, piperidinium), $4.18\left(\mathrm{t}, 8 \mathrm{H}, \mathrm{OC}_{2} \mathrm{H}_{5}\right.$, $J=6 \mathrm{~Hz}$ ), 5.03 (s, $4 \mathrm{H}, \beta$-diketonato), 6.90 (br s, $8 \mathrm{H}$, phenyl), 8.01(br s, $8 \mathrm{H}$, phenyl). Pos. FAB-MS: $m / z 930\left([\mathrm{M}+\mathrm{H}]^{+}-1\right.$ ligand - piperidinium cation), $1189\left([\mathrm{M}+\mathrm{H}]^{+}-\right.$piperidinium cation). Elemental analysis calcd. For $\mathrm{C}_{53} \mathrm{H}_{52} \mathrm{EuF}_{12} \mathrm{NO}_{12}$ : Eu, $11.92 \%$;, $49.93 \% ; \mathrm{H}, 4.11 \%$;, $1.29 \%$. Found: $\mathrm{Eu}, 11.50 \%$; C, $49.77 \%$; $\mathrm{H}, 4.14 \%$; N $1.29 \%$.

\subsection{Data Collection, Refinement and Structural Determination}

Single crystals of piperidinium tetrakis $\left\{1-\left(4^{\prime}\right.\right.$-methoxy or ethoxy phenyl)-4,4,4-trifluoro-1, 3-butanedionato\}europate (III) complexes $\mathbf{2} \mathbf{a}$ and $\mathbf{2} \mathbf{b}$ were obtained from a solution of chloroform/ethanol at room temperature using slow diffusion. The crystallographic data of these complexes were summarized in Table 3. APEX2 software was used for preliminary determination of the unit cell [13]. The determination of integrated intensities and unit cell refinement were performed using the SAINT program [14]. The structures were solved with SHELIXS-2014/7 [15] and subsequent structure refinements were performed with SHELIX-L2014/7 [15].

Table 3. Crystallographic data for the complexes $\mathbf{2 a}$ and $\mathbf{2} \mathbf{b}$.

\begin{tabular}{|c|c|c|}
\hline Crystal Information & $2 a$ & $2 b$ \\
\hline Empirical formula & $\mathrm{C}_{49} \mathrm{H}_{44} \mathrm{EuF}_{12} \mathrm{NO}_{12}$ & $\mathrm{C}_{53} \mathrm{H}_{52} \mathrm{EuF}_{12} \mathrm{NO}_{12}, \mathrm{CHCl}_{3}$ \\
\hline Formula weight & 1218.82 & 1394.30 \\
\hline Temperature & $90 \mathrm{~K}$ & $90 \mathrm{~K}$ \\
\hline Wavelength & $0.71073 \AA$ & $0.71073 \AA$ \\
\hline Crystal system & Monoclinic & Triclinic \\
\hline Space group & C2/c (no. 15) & $P-1$ (no. 2$)$ \\
\hline Unit cell dimensions & $\begin{array}{c}\mathrm{a}=49.553(5) \AA \\
\mathrm{b}=11.2988(12) \AA \\
\mathrm{c}=18.8552(19) \AA \\
\beta=111.599(2)^{\circ}\end{array}$ & $\begin{array}{l}\mathrm{a}=12.9414(12) \AA \\
\mathrm{b}=15.5698(13) \AA \\
\mathrm{c}=17.5075(16) \AA \\
\alpha=69.6130(10)^{\circ} \\
\beta=70.0410(10)^{\circ} \\
\gamma=76.1220(10)^{\circ}\end{array}$ \\
\hline Cell volume & $9815.6(18) \AA^{3}$ & $2880.9(5) \AA^{3}$ \\
\hline $\mathrm{Z}$ & 8 & 2 \\
\hline Density (calculated) & $1.650 \mathrm{~g} / \mathrm{cm}^{3}$ & $1.607 \mathrm{~g} / \mathrm{cm}^{3}$ \\
\hline Absorption coefficient & $1.387 \mathrm{~mm}^{-1}$ & $1.327 \mathrm{~mm}^{-1}$ \\
\hline $\mathrm{F}(000)$ & 4896 & 1404 \\
\hline Crystal size(mm) & $0.45 \times 0.30 \times 0.30$ & $0.30 \times 0.20 \times 0.10$ \\
\hline$\theta$ range for data collection & $1.77^{\circ}$ to $25.03^{\circ}$ & $1.29^{\circ}$ to $25.03^{\circ}$ \\
\hline Index ranges & $-58 \leq h \leq 46,-13 \leq k \leq 13$ & $-15 \leq h \leq 10,-17 \leq k \leq 12$ \\
\hline Reflections collected & $-22 \leq l \leq 21$ & $-20 \leq l \leq 20$ \\
\hline Independent reflections & $8642[\mathrm{R}(\mathrm{int})=0.0308]$ & $9950[\mathrm{R}(\mathrm{int})=0.0223]$ \\
\hline Reflections & $7138\left(25.03^{\circ}\right)$ & $9356\left(25.03^{\circ}\right)$ \\
\hline$[I>2 \operatorname{sigma}(I)]$ & $99.4 \%$ & $97.6 \%$ \\
\hline
\end{tabular}


Table 3. Cont.

\begin{tabular}{ccc}
\hline Crystal Information & $\mathbf{2 a}$ & $\mathbf{2 b}$ \\
\hline Completeness to theta $^{\circ}$ & Empirical & Empirical \\
\hline Refinement method & Full-matrix least-squares on $F^{2}$ & ${\text { Full-matrix least-squares on } F^{2}}^{2}$ \\
\hline Absorption correction & Empirical & Empirical \\
\hline Data/restraints / parameters & $8642 / 0 / 681$ & $9950 / 0 / 752$ \\
\hline Goodness-of-fit on $F^{2}$ & 1.130 & 1.168 \\
\hline Final $R_{1}$ indices $[I>2$ sigma $(I)]$ & $R_{1}=0.0570$ & $R_{1}=0.0361$ \\
\hline $\mathrm{w} R_{2}$ indices (all data) & $\mathrm{w} R_{2}=0.1716$ & $\mathrm{w} R_{2}=0.1090$ \\
\hline
\end{tabular}

\section{Conclusions}

In conclusion, two new europium (III) complexes $\mathbf{2 a}$ and $\mathbf{2} \mathbf{b}$ were successfully synthesized, characterized by ${ }^{1} \mathrm{H}-\mathrm{NMR}$ spectroscopies, positive FAB-Mass, elemental analysis, and their photophysical properties were evaluated. Further, their absolute structures were determined by X-ray analysis. These complexes $\mathbf{2 a}$ and $\mathbf{2 b}$ exhibited strong emission at $614 \mathrm{~nm}$, which could find prominent applications in light emitting devices. The luminescent intensities of the complexes $2 \mathbf{a}$ and $\mathbf{2 b}$ are quite the same. This result implies that the complexes $\mathbf{2} \mathbf{a}$ and $\mathbf{2} \mathbf{b}$ have similar structures. These strong emissions were attributed to the ${ }^{5} \mathrm{D}_{0} \rightarrow{ }^{7} \mathrm{~F}_{2}$ transition of europium (III) ions under UV excitation.

Acknowledgments: We are grateful to the Center for Instrumental Analysis, Kyushu Institute of Technology (KITCIA) for the Pos. FAB mass, 1H NMR spectral measurements, elemental analyses, and single crystal X-ray measurements. This research was financially supported by JSPS KAKENH Grant Number 15K05611.

Author Contributions: All authors contributed equally to this contribution.

Conflicts of Interest: The authors declare no conflict of interest.

\section{References}

1. Binnemans, B. Lanthanide-Based Luminescent Hybrid Materials. Chem. Rev. 2009, 109, 4283-4374. [CrossRef] [PubMed]

2. Hasegawa, Y.; Wada, Y.; Yanagida, S. Strategies for the design of luminescent lanthanide(III) complexes and their photonic applications. J. Photochem. Photobiol. C 2004, 5, 183-202. [CrossRef]

3. Parker, D.; Senanayake, P.K.; Gareth Williams, J.A. Luminescent sensors for $\mathrm{pH}, \mathrm{pO}_{2}$, halide and hydroxide ions using phenanthridine as a photosensitiser in macrocyclic europium and terbium complexes. J. Chem. Soc. Perkin Trans. 2 1998, 2129-2139. [CrossRef]

4. Robinson, M.R.; O’Reganc, M.B.; Bazan, G.C. Synthesis, morphology and optoelectronic properties of tris [(N-ethylcarbazolyl)(3',5'-hexyloxybenzoyl) methane](phenanthroline)-europium. Chem. Commun. 2000, 1645-1646. [CrossRef]

5. Manju, B.; Satish, K.; Taxak, V.B.; Priti, B.; Khatkar, S.P. Synthesis, photoluminescent features and intramolecular energy transfer mechanism of europium (III) complexes with fluorinate $\beta$-diketone ligand and auxiliary ligands. J. Fluorine Chem. 2015, 178, 6-13.

6. Wang, D.; Liu, H.; Fan, L.; Yin, G.; Hu, Y.; Zheng, J. Synthesis and photoluminescent behavior of Eu(III) complexes with 4,4,4-trifluoro-1-(6-methoxy-naphthalen-2-yl)-butane-1,3-dione. Synth. Met. 2015, 209, 267-272. [CrossRef]

7. Kalinovskaya, I.V.; Mirochnik, A.G. Luminescent Properties of Compounds of Europium(III) with Quinaldic Acid and $\beta$-Diketones. Opt. Spectrosc. 2015, 119, 992-995. [CrossRef]

8. Malba, C.M.; Enrichi, F.; Facchin, M.; Demitri, N.; Plaisier, J.R.; Natile, M.M.; Selva, M.; Riello, P.; Perosa, A.; Benedetti, A. Phosphonium-based tetrakis dibenzoylmethane Eu(III) and Sm(III) complexes: Synthesis, crystal structure and photoluminescence properties in a weakly coordinating phosphonium ionic liquid. RSC Adv. 2015, 5, 60898-60907. [CrossRef] 
9. Martins, J.P.; Martín-Ramos, P.; Coya, C.; Silva, M.R.; Eusebio, M.E.S.; deAndrés, A.; Álvarez, A.D.; Martín-Gil, J. Highly luminescent pure-red-emitting fluorinated $\beta$-diketonate europium(III) complex for full solution-processed OLEDs. J. Lumin. 2015, 159, 17-25. [CrossRef]

10. Melby, L.R.; Rose, N.J.; Abramson, E.; Caris, J.C. Synthesis and Fluorescence of Some Trivalent Lanthanide Complexes. J. Am. Chem. Soc. 1964, 86, 5117-5125. [CrossRef]

11. Richardson, F.S. Terbium(III) and europium(III) ions as luminescent probes and stains for biomolecular systems. Chem. Rev. 1982, 82, 541-552. [CrossRef]

12. Zhang, L.; Li, B.; Zhang, L.; Chen, P.; Liu, S. Synthesis, Characterization, and Luminescent Properties of Europium Complexes with Fluorine Functionalized Phenanthroline. J. Electron. Soc. 2009, 156, H202-H207. [CrossRef]

13. APEX2 Version 2009.9, Bruker AXS Inc.: Tokyo, Japan, 2009.

14. SAINT Version 7.68A, Bruker AXS Inc.: Tokyo, Japan, 2009.

15. Sheldrick, G.M. A short history of SHELX. Acta Cryst. A 2008, 64, 112-122. [CrossRef] [PubMed]

(C) 2017 by the authors. Licensee MDPI, Basel, Switzerland. This article is an open access article distributed under the terms and conditions of the Creative Commons Attribution (CC BY) license (http:/ / creativecommons.org/licenses/by/4.0/). 